\title{
Simulation in Higher Education: Choice, Challenges and Changing Practice
}

\author{
Susan Ledger \\ Head of Education, College of Science, Health, Engineering and Education \\ Murdoch University \\ Perth, Australia \\ s.ledger@murdoch.edu.au
}

\begin{abstract}
Advances in educational technologies continue to offer educators choice and challenges across phases of learning and educational settings. Dramatic changes in simulation technologies over the last two decades offer pilots, miners, engineers, doctors and nurses the opportunity to practice the skills required of their profession. However, simulation is yet to be fully embraced within initial teacher education (ITE) to prepare the next generation of teachers. This paper draws on historical literature in the field and the auto ethnographic experiences of the author to examine the benefits, choices and challenges of adopting simulation within ITE. The study includes the re-envisioning of Micro-teaching 2.0 (Ledger \&Fischetti, 2019) and incorporates Gartner's (1995) hypecycle; the life-cycle status of technologies, to represent the historical uptake of simulation in ITE. The study highlights the benefits of simulation as a preparatory tool for developing and empowering graduates with the skills required to perform the art and science of teaching. It challenges the lack of uptake of simulation in ITE programs and calls for more research into the field.
\end{abstract}

Keywords-simulation; micro-teaching; initial teacher education; technology; self-efficacy

\section{INTRODUCTION}

Disciplinary divides continue to exist in higher education policy and practices, due partly to unique academic objectives and the learning cultures of different programs and subject areas [1]. Adoption of technologies such as simulations within these varying disciplines are diverse, dissimilar and often not disseminated across the wider academy. As a result, many institutes find themselves unaware of the technological take-up and range within their own university. Similar issues exist with tracking the overall uptake of technologies across higher education in general. There is a large gap in awareness of technological usage and tools at the local, national and international level. However, these gaps offer opportunity, possibilities and potential collaborative endeavours among staff across disciplines and universities across the globe.

Simulation within this study refers to a range of mixedreality virtual learning environments where the simulation is the classroom not just a tool being used in the classroom. Despite difficulties understanding the construct and applications, simulation have been found to be successful in creating engaged and meaningful learning environments in a range of higher education fields and professional settings. In many contexts, simulations have been used to remove reallife risks, complicated procedures and to replicate real-life scenarios including medicine [2], medical surgery [3], nurse educators patient simulations [4], civil law [5], aviation [6], business management courses [7], and more recently simulation in teacher education [8]. Kraiger [9], concluded that the salience of simulation is not determined by how well the users liked the simulation but how much they learned from the simulation and applied it to their jobs. Moreover [8], build on the work of [10], and suggest that merely participating in simulation is not enough for meaningful learning to take place - "the instructional design features that hold the most weight are performance assessment, task analysis, scenario design, feedback and participant reflection" (p. 5).

My lived experience as a staff member at a university considered an early adopter of technologies, combined with a historical exploration of literature on simulation in initial teacher education (ITE) programs, underpins the research design of this paper. The auto ethnographic and historical snapshot coupled with Gartner's [11] hype-cycle aims to provide insight into the process of adopting simulation in ITE. It captures and highlights the choice, challenges and changing practices and the role simulation may play to better prepare teachers for the diverse and ever changing contexts in which they are positioned.

Universities around the globe have pockets of perfection and innovation and niche fields of study. University disciplines however, may not be familiar with the diverse practices operating across their campus. A recent call to academics within my university revealed 15 staff across the academy disciplines were using various forms of simulation. An embryonic meeting with this diverse group generated much discussion, enthusiasm and vision. The meeting resulted in funding to pursue the formation of a virtual centre for simulation. The virtual centre is charged with scoping the range of simulation practices across the university, exploring the benefits, challenges and re-envisioning of the use of simulation and developing research partnerships in higher education. 
In this paper, I draw from my involvement in this wholeof-university process but focus specifically on simulation in teacher education and the historical literature in the field.

\section{METHOD}

The study highlights the benefits of simulation as a technological tool for developing the art and science of teaching. It challenges the lack of uptake of simulation in ITE and calls for more research into the field. The study provides insight into how one university embeds new simulation technologies within its ITE program and maps this against historical and global trends in the field

The aim of this study is to highlight the choice, challenges and changing practice in ITE. It seeks responses to the following questions:

1. What choice of simulations are being adopted by universities for preparing preservice teachers?

2. What benefits and challenges are faced with the adoption of simulation in ITE?

3. Do historical and contemporary accounts of simulation provide insight for future practice?

The study combines an auto-ethnographic approach to research design with a historical review of literature in the field to map the uptake of simulation in higher education. (ITE) seeks to describe and analyse an auto ethnography approach is used to highlight by personal experience of introducing simulation into initial teacher education. The study will use historical literature to support or counter my experiences to reveal choice, challenges and insight into the adoption of simulation, As a method, this combined approach of auto ethnography and historical literature is considered both process and product [12]. The combined approach attempts to disrupt the binary of science and art, by simply taking a different view toward the subject. Rorty [13], considers these differences as 'issues not to be resolved... but differences to be lived with'. Gartners' [14], hype-cycle is used to triangulate data from auto ethnographic approach and the literature review. The findings will provide a technological snapshot of the uptake and life-cycle of simulation in higher education.

\section{SimULATION IN EDUCATION}

Simulation based education (SBE) is a rapidly developing discipline and field of research [15], it offers greater efficiency and rigour compared with learning through clinical experiences. SBE ensures professional competence before exposure to real-life scenarios. There is emerging evidence of the reliability and validity of assessments using simulation for competency-based tasks, technical skills, application of knowledge, behavioural, communicative and relational capabilities [16].

However, itis difficult to identify when simulation in teacher education first appeared. This is due partly to the ambiguity of the term simulation and gaps in historical records. The definition of the term simulation as described in dictionaries (Collins, Merriam-Webster, Cambridge) can be condensed to the process of simulating something or the product of simulating it. Simulation within an education context relates to something that can be used to teach, practice or reflect on learning and performance [17].

Aldrich [18] describes a learning simulation as an experience designed to develop competence and conviction. This can be achieved by combining modes of entertainment or game elements and instructional or pedagogical elements through either technological or human involvement. Educators have the opportunity to set up a simulated teaching classroom or interactive scenarios involving class settings and staff or parent interactions, to develop mastery of specific skills and behaviours. Simulation affords teaching scenarios that can be practiced and repeated.

Traditional simulation incorporated human elements such as role-plays. This approach primarily involved preservice teachers imitating classroom children whilst being taught by other preservice teachers. In the 1960s, this approach was formally referred to as micro-teaching and combined both entertainment and pedagogical elements controlled by humans.

Historical records reveal early teaching practices favoured a didactic approach representative of Plato's transference of knowledge through listening, observation and emulating what they saw their masters perform, whereas a Socratic approach relied more on relationships and placed responsibility for gaining knowledge on the student [19]. Educationally, the focus has shifted from approaches to teaching, to approaches and domains of learning and associated taxonomies: cognitive - thinking [20], affective emotion/feeling [21], and psychomotor physical/kinaesthetic [22]. From a personal perspective of embedding simulation in ITE, all three domains can be addressed within a simulated learning environment. The ability to adapt and adopt simulations to meet the need of an individual or cohort is timely, particularly given the current scrutiny of the teaching workforce and the growing demand for evidence-based performance [23].

Teaching is often described as an art or science. Axelrod [24] bifurcates instructional strategies into didactic or evocative approaches to teaching. My higher education experience suggests that simulation offers learning environments that can be modified to address both the art (evocative) and science (didactic) of teaching. Typically, these are assessed whilst on practicum within a range of school contexts and under the tutelage of a diverse range of mentor teachers [17]. Simulation, however, helps to mitigate against these contextual differences by providing a controlled learning environment where the performance of preservice teachers (PSTs) can be moderated [25].

Findings drawn from simulation research and observational outcomes [26] highlight the benefit and flexibility of simulation experiences. Simulation affords initial teacher educators the opportunity to create scenarios that are easily adopted for the development of learning domains, skills, behaviours and efficacy of our PSTs. Simulation also offers the opportunity to target the specific 
needs of preservice teachers and identify strengths within their teaching practice.

\section{A. Gartner's Hype Cycle (1995)}

Where does simulation fit within our current technological landscape?

The rapidly accelerating range of new technological innovations will profoundly impact the way we transfer knowledge and educate students, preservice teachers and academics in higher education. Strategic technology trends have the potential to drive significant disruption and deliver significant opportunity. Since 1995, Jackie Fenn (Gartner Institute) introduced Hype cycles to capture and track the over enthusiasm (hype) and subsequent disappointment of introducing technologies. Gartner Inc. is the largest global research and advisory firm of information technology. It's 1995 hype cycle provides a snapshot of the relative maturity of technologies [27] and more importantly reflects peoples attitude toward technology. Cleary \&Burke [28] from Gartner Inc, identified 10 strategic technology trends: Autonomous things; Augmented analytics; AI driven development, Digital twins; Empowered edge; Immersive technologies; Blockchain ledger; Smart spaces; Digital ethics and privacy; and Quantum computers. In the world of business. Gartner's [29]. Market guide for technologies suggests "innovation leaders must evaluate these top trends to identify opportunities, counter threats and create competitive advantage" (p. 1). They predict the way we perceive and interact with technology is undergoing a radical transformation. Conversational platforms, augmented reality, virtual reality and mixed reality are providing more natural and immersive ambient experiences within the digital world. Yet, the uptake of simulation within ITE has not been fully embraced. Using Gartner's [11] 1 hype cycle to map the adoption of Second Life simulation in higher education, Ledger, Power, Rappa, Wong, Hilliard, and Burgess (in press) positioned simulation in the trough of disillusionment (Figure 1). They found that initial adoption of Second Lifesimulated technologies within ITE programs were accompanied with expectations and possibilities; however, in many cases challenges and realities raised questions and concerns and led to limitations and disillusionment. Constant changes in simulation technologies may account for the lack of sustainability involved in the uptake of simulation within ITE.

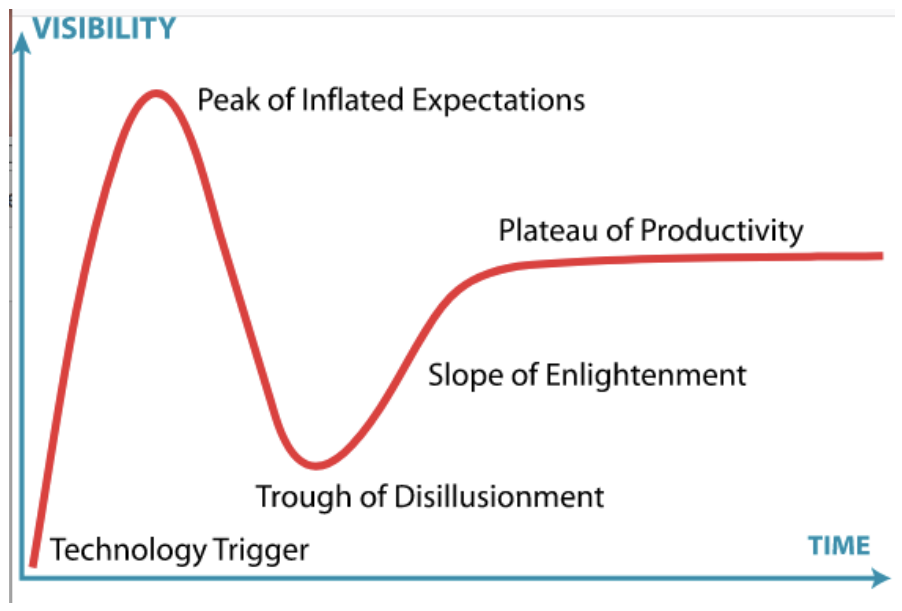

Fig. 1. Gartner Incorporated's hype cycle - represents the maturity, adoption and social application of specific technologies

The unwillingness of ITE programs to adopt simulation and technologies other than teaching tools within a classroom is somewhat understandable given the current standardized and compliance-driven demands embedded within teacher education [23]. We are in an educational environment that PasiSahlsberg termed the Global Education Reform Agenda (GERM) is having great impact on the teaching and learning environment. This borrowed policy, compliance-driven environment restricts risk-taking and creative adoptions within the profession and higher education institutions [23]. ITE program-based initiatives focus on innovative practices rather than technological solutions. Technologies are primarily used to manage curriculum engagement and learning management systems rather than practice-based changes.

\section{Simulated TeChNOLOGY IN ITE}

A major challenge with teaching and learning in school settings is its unpredictable and variable range of experiences for PSTs. This can be overwhelming if the students are faced with scenarios that they are ill-equipped to respond to. SBE mitigates against this lack of preparation as it enables the deconstruction of skills into their component parts at appropriate stages of learning. Without the complexities of real students, simulation provides PSTs a learning environment that facilitates deliberate practice and enables them to focus on mastering basic skills, creatively connect with students, improve communication and feedback capabilities and in turn reduce cognitive load [15].

\section{Choice}

A historical snapshot of simulation used in modern teacher education begins in the early 1960s. Allen and Ryan [30]developed Micro-teaching as a role-play process that facilitated deliberate and reflective practice. The microteaching model incorporated a plan, teach, review, re-plan, re-teach and review cycle. This model has impacted, informed and continued to exist in a range of practices around the globe. In the 1980s, it was used to inform the Stop Video Method [31] when participants paused the video to 
reflect and respond on the context. In the 1990s, the Curry voice simulations offered feedback to the process through the incorporation of a facilitator[31] . During the early 2000s, technological advances began to offer a broader range of simulation. Bradley and Kendall [32] categorized contemporary simulations as single user, mixed reality and multi-user.Single user preprogramed responses includeSimschool, Classroom SIM, At-Risk for High School Educators, Step In, Speak up, Connect.ed [33]; Mixed reality offers synchronous responses such asTeachLivE [8]andTeacher Talk Game. Multi-user virtual environments are asynchronous but allow multiple users; Active World and Second Life.

Most of these forms of simulations are realistic and responsive; however, some incur more costs and time than others. Single user computer simulations can be accessed anywhere and anytime; mixed-reality platforms such as Teachlive and Mursion require booking times, whilst multiuser enables individual use or collaboration with others via computers [34]. All offer situational, scenario-based, roleplay simulations that can be adapted to suit the needs and interests of the user.

Each of the above choices provide opportunities for repeated practice, focused feedback and measurable outcomes of performance. Computer-based simulations provide PSTs with safe, controlled virtual learning environments where they can transfer theory into practice before applying these skills within real-life class contexts.

\section{B. Challenges}

One of the fundamental challenges of simulation relates to its sustainability. New technology simulations remain caught in Gartner's trough of disillusionment phase (Ledger et. al. in press) due partly because of rapidly changing technologies and associated high costs, whereas traditional non-technological simulations such as micro-teaching have reached the plateau of productivity phase and as such are fully embraced by the profession.

Teacher education programs around the globe have been under scrutiny and undervalued since moving into universities. This perceived lack of status, coupled with a quality-driven, compliance-demanding environment within both the profession and higher education, underpins many of the challenges faced when adopting and implementing changes such as the uptake of simulation.

Lack of funding, technological issues, systems-level policy and compliance constraints and lack of engagement or support from colleagues during the early phase of adoption all impacted the extent to which simulation was adopted within my university. These findings reflect similar conclusions from simulation studies around the globe within initial teacher education [35].

Each choice of simulation outlined above has inbuilt challenges. Some require specific hardware, software, training and specialist staff; others require time, patience, support and philosophical underpinnings. But more importantly, the major challenge rests with the acceptance of simulation by the profession itself.

\section{Changing Practice}

Recent calls for changing practice in ITE programs focus on effectiveness, quality and measurable learning gains [36]. Practicums have traditionally provided the 'learning experiences' in which PSTs can practice the complex role of 'being a teacher'. However, recent focus on core elements that constitute teaching effectiveness involve practice architects [10], pedagogies of enactment [37] productive pedagogies; and Quality Teaching Rounds [38]. These programs highlight the need to role-play, evaluate and refine practice based on feedback. These processes can be valueadded and further enhanced with technological options such as simulation.

\section{DISCUSSION}

Emerging technologies and simulation options are offering ITE programs greater choice, challenges and opportunities. Simulation offers educators involved in ITE programs the opportunity to transform and change the traditional preparatory practices afforded graduate teachers. The range of simulation platforms continue to increase with recent mixed-reality options offering real-time synchronous responses that can be accessed from computers anywhere and anytime. However, limited uptake of simulation can be found in Australian teacher education programs, particularly compared to the United States of America [15].

Why is the uptake of simulation so sporadic? If the experiences of implementing simulation within ITE at Murdoch University reflect other contexts, the following factors need consideration: lack of professional support at the national level for simulation coupled with limited local incentives, financial and compliance constraints and sustainability of previous technologies have hindered widespread adoption of simulation within ITE programs.

The historical snapshot of simulation provided in this paper highlights the benefits of simulation across the ages from traditional micro-teaching roleplays in the $1960 \mathrm{~s}$ through to mixed-reality virtual contexts in the 2020s. It shows there is a positive relationship between SBE and learning outcomes and evidence using simulation results in individual satisfaction, self-reported increased knowledge and improved performance [39]. It is an effective technological tool for developing the art and science of teaching [38]. Simulation affords PSTs increased selfefficacy, improved skills, targeted practice, analytical reflections, controlled scenarios, evidence of performance [40] ,safe learning environments and Moreover, it can strengthen critical aspects of teacher preparation [38].

This strong research-based pedagogical backdrop that highlights the benefits of simulation is unfortunately countered by pragmatic constraints including inherent costs, lack of professional acknowledgement and technological issues faced during implementation. Educators tend to overestimate the effect of a technology in the short term but also underestimate the effect in the long term. This paper 
highlights the sustainability of simulation within ITE. If adopted more widespread, simulation offers potentialities and possibilities that could make a significant difference to the way we prepare our future generation of teachers. A wider adoption would see simulation move from Gartner's trough of disillusionment to a plateau of productivity -a level yet to be achieved by previous computer-based simulations.

Murdoch University introduced Microteaching 2.0 within its ITE program. It combines traditional micro-teaching practices with current mixed-reality human in the loop technologies and has resulted in measurable improvement in self-efficacy and performance of its students [38]. It may offer a solution to making simulations more sustainable and lift it out of what could be considered Gartner's trough of disillusionment.

\section{CONCLUSION}

A combination of auto-ethnography reflections and a historical snapshot of simulation in ITE provide insight into factors impacting choice and challenges with regard to implementation of simulation-based education in ITE.

With technological advances increasing exponentially, educators will continue to face technological choice and challenges within their higher education classrooms. Simulation offers opportunity to transform practice in ITE programs by offering a safe, controlled, scenario-based learning environment that targets specific skills, knowledge and behaviours required of PSTs. These controlled contexts offer effective moderation of practice that mitigate against the variability of experiences within the diverse school contexts that graduates currently find themselves facing during practicum experiences.

Simulation is presented as an under-utilized technology within ITE programs that could profoundly impact the quality and efficacy of graduate preservice teachers. The author challenges the lack of uptake of simulation in ITE and calls for more research into the field.

\section{ACKNOWLEDGMENT}

The author would like to acknowledge the University of Central Florida as the original creators of TeachLivE ${ }^{\mathrm{TM}}$ mixed reality learning environment and their commercial partner Mursion TM the simulation platforms adopted by Murdoch University 2017.

\section{REFERENCES}

[1] N. Goolamally and J. Ahmad, "Attributes of School Leaders towards Achieving Sustainable Leadership: A Factor Analysis," J. Educ. Learn., vol. 3, no. 1, pp. 122-133, 2014.

[2] R. L. Kneebone, D. Nestel, C. Vincent, and A. Darzi, "Complexity, risk and simulation in learning procedural skills," Med. Educ., vol. 41 , no. 8, pp. 808-814, 2007.

[3] R. S. Haluck et al., "A virtual reality surgical trainer for navigation in laparoscopic surgery," Stud. Health Technol. Inform., pp. 171176, 2001.

[4] D. L. Rodgers, "High-fidelity patient simulation: a descriptive white paper report," Healthc. Simul. Strateg., vol. 10, no. 4, pp. 68-77, 2007.
[5] R. A. Baron and N. R. Branscombe, Social Psychology. Boston: Pearson Education, Inc., 2012

[6] D. J. Allerton, "Flight Simulation-past, present and future," Aeronaut. J., vol. 104, no. 1042, pp. 651-663, 2000.

[7] W. J. Ritchie, C. J. Fornaciari, S. A. W. Drew, and D. Marlin, "Team culture and business strategy simulation performance," J. Manag. Educ., vol. 37, no. 5, pp. 601-622, 2013.

[8] E. G. Bradley and B. Kendall, "A review of computer simulations in teacher education," J. Educ. Technol. Syst., vol. 43, no. 1, pp. 3-12, 2014.

[9] H. Aguinis and K. Kraiger, "Industrial and Organizational Psychology Programme at the University of Colorado at Denver," Int. J. Sel. Assess., vol. 5, no. 1, pp. 69-79, 1997.

[10] J. M. Gore and J. M. Bowe, "Interrupting attrition? Re-shaping the transition from preservice to inservice teaching through Quality Teaching Rounds," Int. J. Educ. Res., vol. 73, pp. 77-88, 2015.

[11] R. Michaelson, "The Trough Of Despair And The Slope Of Enlightenment: Gartner's Hype Cycle And Science Fiction In The Analysis Of Technological Longings.," in UKAIS, 2014, p. 46.

[12] C. Ellis, T. E. Adams, and A. P. Bochner, "Autoethnography: an overview," Hist. Soc. Res. Sozialforsch., pp. 273-290, 2011.

[13] A. Jenness, "Social influences in the change of opinion," J. Abnorm. Soc. Psychol., vol. 27, no. 1, pp. 29-34, 1932.

[14] S.-C. Chen, C.-C. Wu, and S. Miau, "Constructing an integrated einvoice system: the Taiwan experience," Transform. Gov. People, Process Policy, vol. 9, no. 3, pp. 370-383, 2015.

[15] J. M. Weller, D. Nestel, S. D. Marshall, P. M. Brooks, and J. J. Conn, "Simulation in clinical teaching and learning," Med. J. Aust., vol. 196, no. 9, p. 594, 2012.

[16] L. Koegel, R. Matos-Freden, R. Lang, and R. Koegel, "Interventions for children with autism spectrum disorders in inclusive school settings," Cogn. Behav. Pract., vol. 19, no. 3, pp. 401-412, 2012.

[17] M. Paull, N. Lloyd, S. A. Male, and T. Clerke, "Engineering work integrated learning placements: the influence of capitals on students' access," J. High. Educ. Policy Manag., vol. 41, no. 5, pp. 534-549, 2019.

[18] S. McKenney and T. C. Reeves, Conducting educational design research. Routledge, 2018.

[19] K. M. Zeichner, Educating teachers for cultural diversity. National Center for Research on Teacher Learning, Michigan State University ..., 1993.

[20] J. F. Marran, "An action vocabulary for thinking spatially: The national geography standards and defining what students should know," J. Geog., vol. 94, no. 4, pp. 462-465, 1995.

[21] D. Nahl and D. Bilal, Information and emotion: The emergent affective paradigm in information behavior research and theory. Information Today, Inc., 2007.

[22] D. Krathwohl and A. H. P. Domain, "Assignments. Pk."

[23] N. Bahr and S. Mellor, "Building quality in teaching and teacher education," 2016.

[24] D. Axelrod, "Post-Burkhead: The state of the art or science of budgeting." JSTOR, 1973.

[25] L. A. Dieker, J. A. Rodriguez, B. Lignugaris/Kraft, M. C. Hynes, and C. E. Hughes, "The potential of simulated environments in teacher education: Current and future possibilities," Teach. Educ. Spec. Educ., vol. 37, no. 1, pp. 21-33, 2014.

[26] C. Straub, L. Dieker, M. Hynes, and C. Hughes, "TeachLive national research project," Retrieved, vol. 12, p. 2014, 2014.

[27] T. Beran, "Research Advances in Conformity to Peer Pressure: A Negative Side Effect of Medical Education," Heal. Prof. Educ., vol. 1, no. 1, pp. 19-23, 2015.

[28] R. Martens, "Strategies for Adopting Additive Manufacturing Technology Into Business Models," 2018.

[29] W. M. P. van der Aalst, M. Bichler, and A. Heinzl, "Robotic process automation." Springer, 2018.

[30] A. Perlberg, "Microteaching: a new procedure to improve teaching and training," Br. J. Educ. Technol., vol. 1, no. 1, pp. 35-43, 1970. 
[31] T. Kato and T. Tamaki, "Wireless communication system for detecting location of the node." Google Patents, 30-Jun-2005.

[32] J. Kuchar et al., "Evaluation of a numerical model of the BritishIrish ice sheet using relative sea- level data: implications for the interpretation of trimline observations," J. Quat. Sci., vol. 27, no. 6, pp. 597-605, 2012.

[33] K. R. Narayanan, R. J. Martin, and J. Gibson, "Controlling a device connected to first and second communication path wherein device is also connected to third communication path via a bypass link." Google Patents, 08-Mar-2011.

[34] H. M. Marks, "Student Engagement in the Classrooms of Restructuring Schools.," 1995.

[35] A. I. Dann, "1. National Deficits in Teacher Preparation Programs."

[36] L. Blue and C. O'Faircheallaigh, "Indigenous Autonomy And Financial Decision-Making In Communities," 2018.

[37] E. Kazemi, M. Franke, and M. Lampert, "Developing pedagogies in teacher education to support novice teachers' ability to enact ambitious instruction," in Crossing divides: Proceedings of the 32nd annual conference of the Mathematics Education Research Group of Australasia, 2009, vol. 1, pp. 12-30.

[38] S. Ledger and J. Fischetti, "Micro-teaching 2.0: Technology as the classroom," Australas. J. Educ. Technol., 2020.

[39] S. W. Bradley, K. Artz, and J. Hulett, "The innovation necessity: Evidence from microcredit in the Dominican Republic," J. Int. Dev., vol. 24, pp. S112-S121, 2012.

[40] D. Kaufman and A. Ireland, "Enhancing teacher education with simulations," TechTrends, vol. 60, no. 3, pp. 260-267, 2016. 